\title{
BIOAVAILABILITY ENHANCEMENT AND LIPID NANOCARRIER BaSEd Delivery of PEPTIDES AND Proteins
}

\author{
Sunita Dahiya ${ }^{1 *}$ and Rajiv Dahiya ${ }^{2}$ \\ ${ }^{1}$ Department of Pharmaceutical Sciences, School of Pharmacy, University of Puerto Rico, Medical Sciences \\ Campus, PR-00936, USA \\ ${ }^{2}$ School of Pharmacy, Faculty of Medical Sciences, The University of the West Indies, St. Augustine, \\ Trinidad \& Tobago, West Indies \\ *E-mail: sunita.dahiya@upr.edu \\ Tel.: +1 7877582525 ext. 5413.
}

Received: Jul 03, 2020 / Revised: Sep 24, 2020 / Accepted: Sep 25, 2020

\begin{abstract}
Peptides and proteins are vital biomacromolecules that perform several bodily functions in various physiological and biological processes. Being biocompatible and biodegradable, these macromolecules are considered promising platforms for delivery of drugs and genes. However, peptides and proteins suffer from major limitations including enzymatic degradation, short circulation half-lives, and poor membrane permeability that leads to poor bioavailability, challenging their effective delivery. This article briefly discusses the inherent challenges in peptide and protein delivery along with strategies for bioavailability enhancement and lipid nanocarriers as prospective systems for peptide and protein drug delivery.
\end{abstract}

Key words: Peptide delivery, Delivery challenges, Bioavailability enhancement, Lipid nanocarriers.

\section{INTRODUCTION}

Peptides and proteins are vital macromolecules that perform numerous biofunctions in the body's major physiological and biological processes [1]. Proteins can be employed for therapeutic delivery as unique biocompatible and biodegradable macromolecules with low toxicity and serve as a platform for delivery of small molecule drugs and genes. Recent advances in synthetic and chemical biology have led to the creation of tailor-made or engineered protein materials for delivery. For example, human antibodies, chimeric proteins, and new protein scaffolds for effective therapies of several ailments including cancer, diabetes, infection, and inflammatory diseases [2]. Human insulin, approved by the US Food and Drug Administration (FDA) in 1982, was the first commercially available recombinant therapeutic protein, and has since become the major therapy for diabetes mellitus type I and type II [3].
Recently, proteins and peptides have gained much attention as potential treatments for dreadful and traditionally incurable diseases such as cancer, AIDS, dwarfism and autoimmune disorders and also as diagnostics. This prompted scientists to synthesize these bioactives in laboratories employing diverse techniques [4-8]. Most commonly, therapeutic peptides and proteins are administered via invasive parenteral routes that have many drawbacks including painful delivery, higher costs and possible toxicity [9]. Research efforts are underway for finding more effective, easier and safer alternative non-invasive routes such as oral, buccal, transdermal, nasal, pulmonary, ocular, and rectal for administering proteins and peptides with only limited clinical success [10]. Despite enormous therapeutic potential, peptides and protein macromolecules suffer from several drawbacks which pose major challenges in delivery of these macromolecules. 
Extensive research efforts are being directed toward developing various strategies such as permeability enhancement, enzyme inhibition, protein structure modification and protection by encapsulation to overcome these obstacles [11]. Also, recent nanotechnological advancements have led several formulations to clinical consideration [12].

\section{Inherent problems and delivery challenges of peptide and protein biomacromolecules}

Since the late $20^{\text {th }}$ century numerous therapeutic proteins and peptides have emerged in the market. Although peptide and protein therapeutics possess high impact in the health industry, delivery of these macromolecules is limited due to several factors such as large molecular size, hydrophilic nature, and enzymatic cleavage. Compared with the conventional small-molecule drugs that continue to dominate the overall pharmaceutical market, protein therapeutics offer the advantages of higher specificity, greater activity, and lower toxicity [13]. The high specificity of proteins often requires maintenance of structural complexity of these molecules, making them difficult to modify and/or formulate. Additionally, the susceptibility to enzymatic degradation, short circulation half-lives, and poor membrane permeability pose significant barriers for effective delivery of many therapeutic proteins. These unfavorable intrinsic characteristics of proteins need to be counterbalanced by designing appropriate delivery strategies or platforms for achieving high therapeutic performance [14] Inappropriate formulation design can cause degradation, denaturation, and/or aggregation of the protein molecules, causing both immunogenic side effects after administration and eventual loss of pharmacological activity [15]. From a therapeutic perspective, proteins are highly potent with specific mechanisms of action. The chemical structures of protein allow them to perform specific reactions in the body, increasing efficacy and decreasing undesirable side effects [12]. Despite these advantages, products of protein therapeutics must overcome the hurdles posed by high molecular weight, short half-lives, instability, and immunogenicity. Therefore, employing proteins for therapeutic purposes face in vivo consequence like short plasma half-life, which requires repeat administrations, chemical and physical instability, rapid degradation in the stomach and intestinal environment, and retention by the impermeable mucosal tissues in the intestine that hinder oral protein administration. Biotechnology-enabled peptide and protein drugs can be produced relatively economically, however, they face physiochemical and biological barriers leading to low bioavailability, limiting their use as therapeutic agents [16]. Challenges and requirements of peptides and proteins in delivery of therapeutic agents are presented in Figure 1.

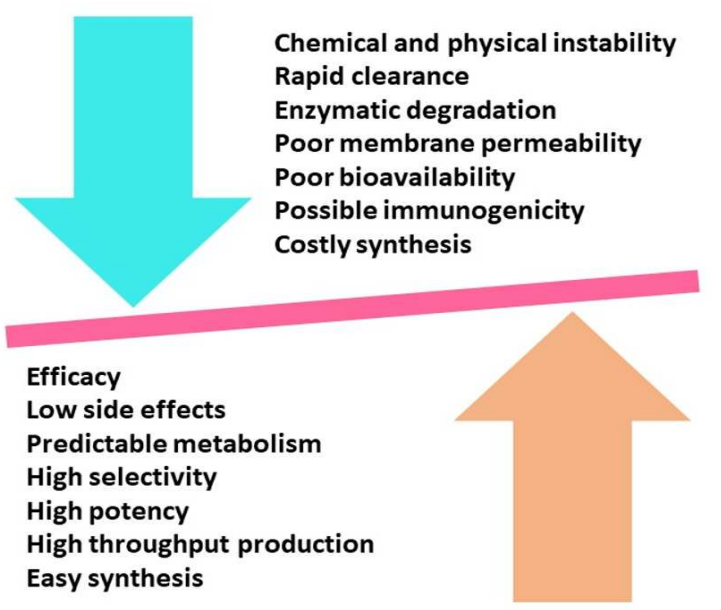

Fig. 1. Challenges and requirements of peptide and protein delivery

\section{Bioavailability enhancement strategies}

Several strategies have been employed to improve current limitations and enhance therapeutic efficacy of therapeutic peptides and proteins which including use of penetration enhancers, enzyme inhibitors, encapsulation, chemical modification, and altered administration routes [17]. Furthermore, while nearly all existing biologic drugs were developed against cellular or extracellular targets, the ability for biologic drugs to enter cells and intracellular compartments can significantly broaden their utility for a vast number of existing targets [18]. Therefore, efforts of scientists focus on improving protein properties by exploring ways to protect proteins from the effects of enzymes in the biological environment, and thus prolonging in vivo half-life, increase absorption and decrease metabolic rate [19].

\section{Permeation enhancers}

Permeation enhancers are used to promote the passage of a pharmacologically-adequate quantity of peptide or protein through the mucosal membranes [20]. Although the 
mechanism of penetration enhancement remains ambiguous, the literature report three different mechanisms: (i) reduction of the barrier functions of mucosal membranes by altering the structure or properties of mucosal membranes; (ii) changing the thermodynamic activity of proteins and peptides; (iii) protecting peptides and proteins from proteolytic activity. Most penetration enhancers function by causing a perturbation of membrane integrity [21]. The medium-chain C8, C10 and C12 fatty acids like caprylate, caprate and laurate, respectively and lectins are widely used permeation enhancers that aids to increase the absorption of peptides and proteins [22]. Co-administration of cellpenetrating peptides (CPPs) can enhance oral absorption of insulin due to due resistance of $d$ amino acids to proteases [23]. Surfactants like sodium dodecyl sulphate causes altered cell morphology and irreversible damage to cell membrane [24] whereas bile salts like sodium cholate could cause cellular damage after longterm use, which disfavored their application as permeation enhancer [25].

\section{Enzyme inhibitors}

The enzymes are considered to be one of the dominant factors in controlling bioavailability of given proteins and peptides due to their high sensitivity to different types of enzymes present in the body [26]. A suitable enzyme inhibitor is chosen according to the type of interest and the site of protein distribution. Many protease inhibitors have been investigated and used for peptide and proteins delivery [27]. However, long-term use of enzyme inhibitors is not desirable as it may disrupt the protein absorption system and leads to the absorption of unwanted proteins, disturb the digestion of nutritive proteins, and incite the secretion of protease in the body as a result of feedback regulation [28]. Soybean trypsin inhibitor (FT448), which is a potent and specific inhibitor of chymotrypsin, plays some role in enhancing the absorption. Examples of enzyme inhibitors are aprotinin which inhibits trypsin, chymotrypsin, and plasmin; puromycin that inhibits serine and metallopeptidases; bacitracin which inhibits trypsin and pepsin, aminopeptidase $\mathrm{N}$; and $\mathrm{N}$ acetylcysteine that inhibit aminopeptidase [17].

\section{Chemical modification}

Chemical modification is commonly used strategy to enhance the bioavailability of protein and peptide drugs by employing the usage of direct structural modifications, which include cyclization, amino acid substitution, conjugation to polyethylene glycol (PEG) polymer chains (PEGylation), glycosylation, and lipidization [29]. Among these, PEGylation and glycosylation have shown improved absorption through biological membranes, along with conferring structural stability, increased systemic stability, increased efficacy, improved safety profile, reduced immunogenicity and thereby enhanced bioavailability of proteins and peptides. Approved PEGylated interferon products including peginterferon alfa-2a (Pegasys, Genetech) and peginterferon alfa-2b (PEGIntron, Merck) for hepatitis $\mathrm{C}$, and peginterferon beta-1a (Plegridy, Biogen Idec) for multiple sclerosis prove commercial successes of PEGylation approach [30]. PEGylation can also be used to develop prodrugs. Prodrugs, being pharmacologically inactive and metabolized into active drugs under suitable physiological conditions after administration, provides an alternative strategy to circumvent poor solubility, improving pharmacokinetics and minimizing toxicity of protein and peptide-based drugs [31]. Advanced PEGylation technologies allow PEG to be readily engineered in various shapes and sizes, with high site-specificity and purity; thereby reducing immunogenicity and protein deactivation during conjugation. Additionally, peptide stapling has shown advantages in increasing a peptide's stability, cellular penetration, and binding affinity by locking the conformation of the peptide through multiple, synthetic, hydrocarbon backbones. Rapid elimination of proteins from the blood circulation and their degradation by enzymes limit their routine use as a drug. Fast protein elimination may be owing to the rapid renal clearance of proteins having a low molecular weight of $40 \mathrm{kDa}$ or less. This means increasing the molecular weight of low molecular weight therapeutic molecules to over $40 \mathrm{kDa}$ may reduce elimination rate. This principle was utilized by some researchers through conjugating proteins with water soluble polymers, which in turn slowed reduced renal clearance, thereby prolonging the survival of the drug in the bloodstream [32]. The in vivo short half-life of proteins may result from the immune response mechanism. Further, the structural modification employing combination of proteins and polymers may hinder opsonin and antigenprocessing cells from recognizing these proteins. Therefore, the expulsion of proteins from the 
general circulation by phagocytosis is prevented. Interestingly, polymers that conjugate with proteins creates a steric barrier that impedes the protein degradation by clashing its binding with the active sites of proteases. Various polymers have been used for increasing protein stabilization. Among all, the most preferred is PEG because it is biocompatible, inexpensive and approved by regulatory authorities.

\section{Encapsulation}

Protecting proteins and peptides in polymeric reservoirs or carrier systems is promising approach for protein delivery [33]. These particulate drug delivery systems provide several advantages, such as protecting the encapsulated protein against the effect of enzymes and controlling the site and speed of protein release which help in avoiding undesirable side effects. Different techniques have been investigated and used for encapsulating therapeutic proteins, especially via use of the lipid-based or polymer-based nanocarriers.

\section{Altered Routes of Administration}

Most commonly, therapeutic proteins and peptides were delivered by subcutaneous (SC, intramuscular (IM), and intravenous (IV) injections. However, using intravenous injection for protein administration raises many problems as it is painful, uncomfortable and expensive for the patients. In addition, therapeutic proteins are rapidly cleared from the blood stream which necessitates repeating doses that may lead to toxic effects [33]. Protein administration via subcutaneous injection may lead to complete bioavailability that may be in fact, quite lower depending on many factors, such as drug molecular weight, injection site, muscular activity and pathological conditions. Relatively higher patient non-compliance with invasive injectable routes have led research efforts toward finding more effective, easier and safer alternative routes for protein and peptide administration, thus the concept of peptide and protein administration via non-invasive routes such as oral, buccal, nasal, pulmonary, transdermal, ocular, and rectal routes emerged. Till date, there has been extensive research efforts for the delivery of various peptide and protein therapeutics through various routes employing numerous strategies and techniques, however, the oral, nasal and pulmonary routes have been the primary non-invasive routes of protein delivery investigated so far. The field of protein delivery research gained increasing interests despite the fact that the bioavailability of peptides and proteins have been still very low in most of the non-invasive routes tested. The high cost of many of these complex molecules also may limit the number of protein drugs that would be economically feasible to deliver via these non-invasive routes. The route of administration of a drug has a significant impact on its therapeutic result. Major challenges to the non-invasive delivery of these macromolecules are summarized in Table 1.

Table 1. Non-invasive routes of peptide and protein administration and associated challenges

\begin{tabular}{|l|l|}
\hline Non-invasive route & Major delivery challenges \\
\hline Oral & $\begin{array}{l}\text { Epithelial cell barrier, protease degradation, degradation in extreme pH conditions, low } \\
\text { bioavailability }\end{array}$ \\
\hline Buccal & $\begin{array}{l}\text { Limited retention of dosage form in buccal pouch, presence of drug metabolizing enzymes } \\
\text { like oxidases, reductase, cyclooxygenases, peptidases at the delivery site }\end{array}$ \\
\hline Transdermal & $\begin{array}{l}\text { Presence of stratum corneum as primary barrier, degradation by protease, limited surface } \\
\text { area }\end{array}$ \\
\hline Pulmonary & $\begin{array}{l}\text { Epithelial cell barrier, degradation by protease, presence of alveolar macrophages, } \\
\text { delivery of only limited amount of protein per dose }\end{array}$ \\
\hline Ocular & $\begin{array}{l}\text { Influenced by tear turnover, degradation by protease, protein binding, possible corneal } \\
\text { irritation, low patient acceptance }\end{array}$ \\
\hline Nasal & $\begin{array}{l}\text { Low bioavailability, degradation by protease, variable absorption, possible irritation of } \\
\text { nasal mucosa }\end{array}$ \\
\hline Rectal & $\begin{array}{l}\text { Elimination of drug during bowel movements, limited surface area, low patient } \\
\text { compliance }\end{array}$ \\
\hline
\end{tabular}

Lipid-based nanocarriers for peptides and protein delivery Liposomes
Since their discovery in 1964, liposomes have been one of the most successful lipid-based nanocarrier with several FDA-approved 
liposomal products and many more under clinical development for various human diseases. Liposomes are defined as vesicles with an aqueous inner core surrounded by one or more bilayers of amphiphilic phospholipids with size range from $20 \mathrm{~nm}$ to few microns [34]. The schematic of drug-loaded liposome is illustrated in Figure 2a. Among the wide variety of lipids, amphiphilic lipids that are able to self-assembly, such as phospholipids, phosphatidylglycerol derivatives and both saturated and unsaturated fatty acids, are the most commonly used for producing liposomes. Additionally, the inclusion of polymers and surfactants into their structure is also possible [35]. Recently, the use of special lipids has led to the formation of nanostructures named as archeosomes i.e. diether or tetraether lipids and niosomes i.e. polyoxyethylene alkyl ethers were developed to facilitate the entrapment of peptides and proteins therapeutics [36].

\section{Solid lipid nanoparticles}

Solid lipid nanoparticles (SLNs) were developed in mid 1990s as an alternative nanocarrier system to overcome some drawbacks of liposomes and other carriers. As SLNs prepared

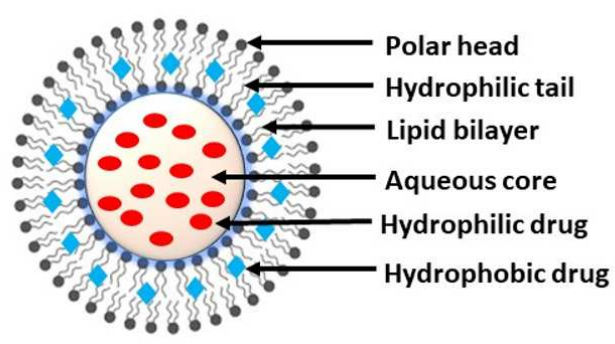

(a) either with physiological lipids or lipid molecules with a history of safe use in human medicine, attract increasing attention as colloidal drug carriers. Under optimized conditions they can be produced to incorporate lipophilic or hydrophilic drugs as illustrated in Figure $\mathbf{2 b}$ to fulfil the requirements for an optimum particulate carrier system [37]. Advantages of SLNs includes the use of physiological lipids, the avoidance of organic solvents, a potential wide application spectrum (dermal, oral, intravenous) and the high pressure homogenization as an established production method. Additionally, improved bioavailability, protection of sensitive drug molecules from the outer environment (water, light and even controlled release characteristics) were claimed by incorporation of poorly water soluble drugs in the solid lipid matrix. Common disadvantages of SLNs are lipid polymorphism, unpredictable gelation tendency, unexpected dynamics of polymorphic transitions and their inherent low encapsulation due to the crystalline structure of the solid lipid [38]. A lectin-modified and insulin-coated SLN was found to deliver insulin after administration to the small intestine [39].

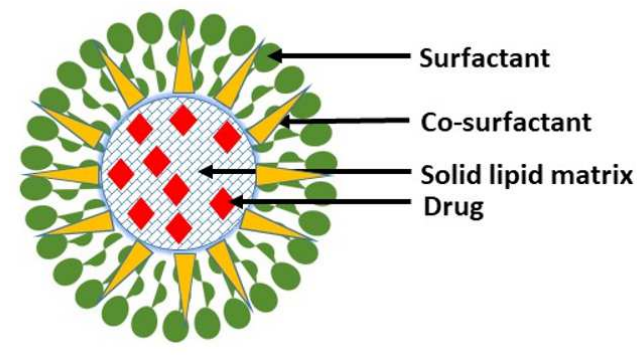

(b)

Fig. 2. (a) Typical structure of liposome; (b) Typical structure of SLN.

\section{Nanostructured lipid carriers}

A new generation of nanostructured lipid carriers (NLCs) consist of a lipid matrix with a special nanostructure that possesses improved drug loading while firmly retaining the drug during storage. NLCs can be produced by mixing solid and liquid (oil) lipids using high-pressure homogenization and the process can be modified to yield lipid particle dispersions with solid structure, enabling better drug accommodation from $30-80 \%$ [40]. The NLC system minimizes or avoids some potential problems associated with SLNs; the major advantage being its ability to incorporate large quantities of drugs as a result of formation of a less ordered lipid matrix with many imperfections. NLCs have been mainly used for topical, oral and parenteral administration. NLCs have advantages over liposomes and nanoemulsions in terms of ease of preparation, high drug loading capacity, lower water content and sustained drug release properties. Three types of NLCs have been described: (i) imperfect crystal: small amounts of chemically different liquid (oil) lipids mixed with solid lipids. This incompatibility leads to imperfections in the crystal order inside the lipid core allowing higher drug loading as illustrated in Figure 3 [41]. (ii) amorphous: The particles are solid but in an amorphous state. Crystallization upon cooling is avoided by the 
addition of lipids with a special structure e.g. hydroxyl-octacosanyl-hydroxystearate and isopropylmyristate thereby preventing consequent drug expulsion during storage. (iii) multiple: also referred as multiple Oil in Fat in Water $(O / F / W)$ carriers. The solubility and dispensability of many lipophilic drugs in a liquid lipid are higher than in a solid lipid. Therefore, an excess amount of oil is mixed with the solid lipid. Above the solubility, a phase separation occurs with the formation of oily nanovesicles within the solid lipid matrix while the drug dissolve in the oil and is protected by the surrounding solid lipids. The methods used to produce NLCs for the delivery of peptides and proteins are $W / O / W$ double emulsion and the hot high pressure homogenization technique [42].

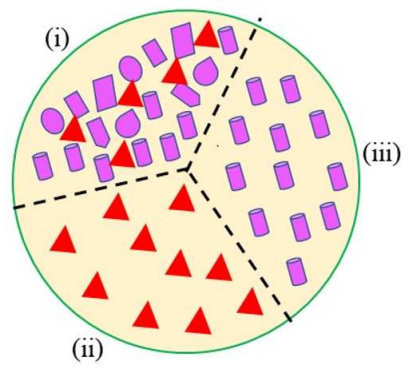

Fig. 3. Types of NLCs. (i) imperfect crystal, (ii) amorphous, (iii) multiple

\section{Lipid Nanocapsules}

Lipid nanocapsules (LNCs) range between 20 and $100 \mathrm{~nm}$, are biomimetic and synthetic nanocarriers used in drug delivery bioimaging [43]. The typical LNCs contain a oily (lipid) core composed of medium-chain triglycerides, surrounded by a surfactant shell made of lecithin and PEGylated surfactants (Figure 4). The oily phase is composed of triglycerides of capric and caprylic acids like Labrafac ${ }^{\circledR}$ WL 1349 . The hydrophilic surfactant, Kolliphor ${ }^{\circledR} H S 15$ is a derivative from a mixture of free PEG 660 and PEG 660 hydroxystearate. The aqueous phase consists of deionized water containing sodium chloride. Another surfactant, Lipoid $\AA$ S75-3 composed of $70 \%$ of phosphatidylcholine soya bean lecithin, is also added to significantly increase LNCs' stability. The choice of the oily phase and the surfactant can be modulated according to the properties of the encapsulated drug [44]. All components mentioned above are FDA approved for oral, topical and parenteral administration.

The preparation of LNCs involves a phase inversion temperature process, which is a solvent free and low energy process. Initially, the components are mixed together; the emulsion is then heated and cooled several times between $90{ }^{\circ} \mathrm{C}$ and $60{ }^{\circ} \mathrm{C}$ to obtain reversible emulsion phase inversions. Higher temperatures lead to $W / O$ emulsions following the dehydration of the polar surfactant heads while lower temperatures lead to classical $O / W$ emulsions. After several temperature cycles, rapid dilution with cold water or simple rapid cooling without dilution is performed at temperature corresponding to the phase inversion zone which further elaborates and fix the final LNC dispersion. The last formulation steps lead to an instantaneous and irreversible dispersion of the bicontinuous system which characterizes the "Phase Inversion Zone". The development of "Aqueous-Core Lipid Nanocapsules' provides an additional tool to encapsulate hydrophilic peptides and protein drugs [45]. The incorporation of hydrophilic molecules can be performed in either by incorporating hydrophilic molecules in the internal aqueous phase of the $W / O$ normal emulsion or by injecting a small volume $(2 \% \mathrm{v} / \mathrm{v}$ or less) of a very concentrated aqueous solution at the phase inversion temperature, after the temperature cycling and before the oil dilution. In this way, the degradation of molecules, due to the exposure to the temperature during the process, can be avoided. LNCs provide drug protection against biological degradation with an efficient drug loading while exhibiting sustained release to the site of action. Moreover, the PEGylated surface of the LNCs displays a stealth effect with inhibitory effect on Pglycoprotein. All these benefits including their structural flexibility according to the drug to be encapsulated, make the LNCs attractive carriers for peptides. Recent works have emerged a new generation of LNCs providing an interesting alternative to encapsulate hydrophilic drugs with a relatively good yields yet requiring longterm toxicity studies to ensure safety of LNCs.

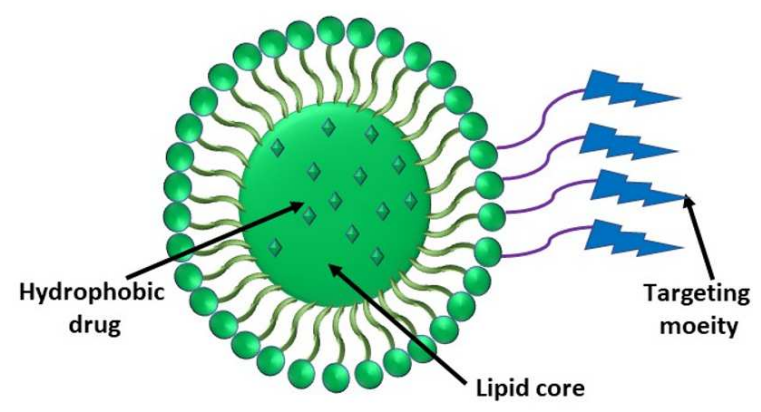

Fig. 4. A typical LNC with oily core 


\section{Microemulsions and nanoemulsions}

Microemulsions are thermodynamically stable transparent isotropic dispersions having low viscosity. Microemulsions consist of oil and water stabilized by an interfacial film of surfactant molecules, typically in conjunction with a co-surfactant. Usually, the inner phase, either oil $(o / w$ emulsions) or water $(w / o$ emulsions) as shown in Figure 5. These emulsions range upto $10-100 \mathrm{~nm}$ in size. Microemulsions have been proposed to enhance the oral bioavailability of drugs, including hydrophilic peptides and protein that can be successfully incorporated into the dispersed aqueous phase of $w / o$ microemulsion droplets where it affords some protection against enzymatic degradation when administered orally [30]. Neoral ${ }^{\circledR}$, an oral microemulsion, is an immunosuppressant medicine used to prevent organ rejection after a kidney, liver, or heart transplant and to treat severe psoriasis or severe rheumatoid arthritis. It is a microemulsion preconcentrate containing a surfactant, lipophilic and hydrophilic solvents and ethanol. The presence of a surfactant, and in some case a cosurfactant, and medium chain diacylglycerols can be related to the increase of membrane permeability, thereby increasing the drug uptake [46]. Considerable dosage form development activity has focused on the formulation of lecithin-based microemulsions as lecithin is a naturally occurring biological surfactant and a major component of membrane lipids which is non-toxic and safe to use [47].

Nanoemulsions are fine $o / w$ dispersions, having droplets of size range 100-400 nm. Nanoemulsions were introduced during the 1950s for the parenteral nutrition using fatty vegetable oils like soy oil or middle chain triacylglycerols as lipid phase typically constituting $10-20 \%$, phospholipids as stabilizers in $0.6-1.5 \%$, and glycerol as osmolarity regulation in $2.25 \%$ [48]. Later on, these systems recognized as potential carriers for lipophilic drugs with commercial success, for example, etomidate (Etomidat-LipuroR) and diazepam (Diazepam-LipuroR). However, an important drawback related to nanoemulsions is the limited controlled release properties, due to the small size and the liquid state of the carrier. For most drugs, a rapid release will be observed. It has been estimated that retarded drug release requires very lipophilic drugs, i.e. the $\mathrm{K}_{\mathrm{o} / \mathrm{w}}$ should be larger than 106:1 [47]. Particular examples of nanoemulsions are the self-nanoemulsifying drug delivery system (SNEDDS), defined as isotropic mixtures of an oil, surfactant, cosurfactant and drug, which form fine $o / w$ nanoemulsions when introduced into aqueous media under mild agitation. The digestive motility of the stomach and intestine provides the agitation required for self-emulsification in vivo. Factors controlling the in vivo performance of SNEDDS include their ability to form small droplets of oil and the polarity of the oil droplets to promote faster drug release into the aqueous phase. Since a relatively high concentration of surfactants is generally employed in the SNEDDS formulation, toxicity of the surfactant being used should be considered. Peptides and proteins associated to microemulsions and nanoemulsions include cyclosporine A, immunoglobulin $\mathrm{G}$ insulin, and fusion protein vaccine [10].
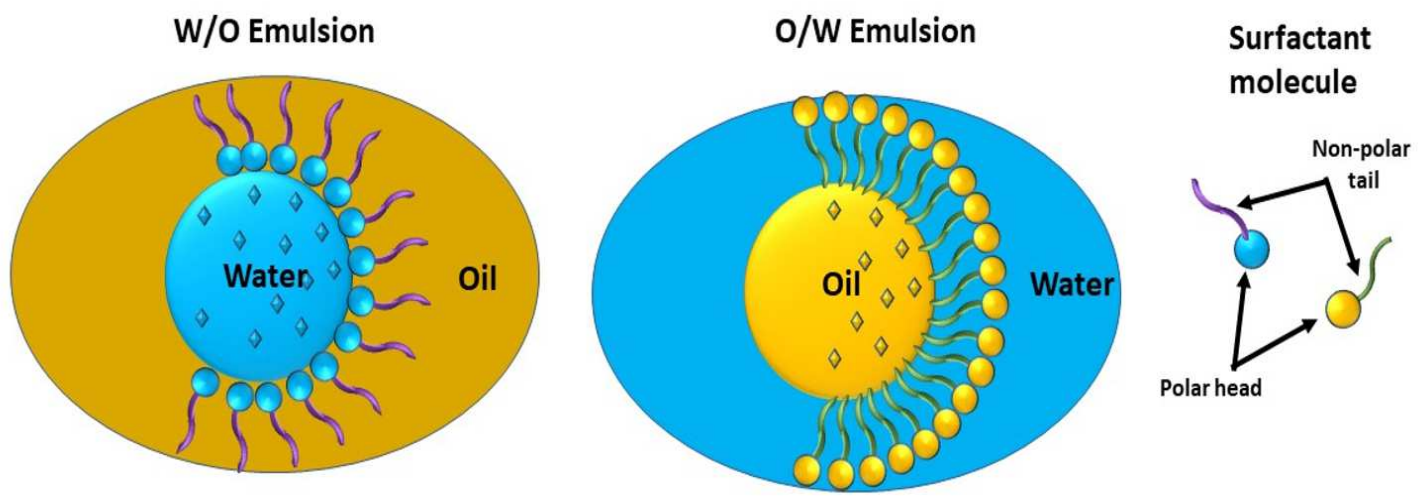

Fig. 5. Typical $o / w$ and $w / o$ microemulsion and nanoemulsion. The orientation of surfactant molecules depends on dispersed and continuous phase. In $w / o$ emulsion, the polar head of the surfactant molecule orient to face dispersed/internal water phase and non-polar tails of surfactant molecule orients to face the continuous/external oil phase, and vice-versa for the $o / w$ type of emulsion 


\section{Market forecast of peptide and protein therapeutics}

The global peptide therapeutics market is valued at 28500 million USD in 2020 and will reach 41900 million USD by the end of 2025 , growing at a CAGR of $5.0 \%$ during 2021-2025 [49]. According to the report of alliedmarketresearch.com, the global oral proteins and peptides market accounted for $\$ 643$ million in 2016, and is anticipated to reach $\$ 8,233$ million by 2028 , registering a compound annual growth rate (CAGR) of $11.7 \%$ from 2022 to 2028. "Oral Proteins and Peptides Market (3rd Edition, 2018-2030" report added to ResearchAndMarkets.com's provides an extensive study on the current market landscape of orally administrable protein/peptide-based therapeutics, featuring a comprehensive discussion on the future potential of this evolving market [50]. While more than half of these pipeline candidates are in the discovery/preclinical stages, around $28 \%$ of drug candidates are presently in advanced stages of evaluation i.e. phase II and above [51].

\section{REFERENCES}

1. Berg JM, Tymoczko JL, Stryer L. Biochemistry. 5th edition, W. H. Freeman: New York, 2002.

2. Yin L, Yuvienco C, Montclare JK. Protein based therapeutic delivery agents: Contemporary developments and challenges. Biomaterials. 2017;134: 91-116. doi:10.1016/j.biomaterials.2017.04.036

3. Landgraf W, Sandow J. Recombinant human insulins Clinical efficacy and safety in diabetes therapy. Eur Endocrinol. 2016;12(1):12-17. doi:10.17925/EE.2016.1 2.01.12

4. Dahiya R, Rampersad S, Ramnanansingh TG, et al. Synthesis and bioactivity of a cyclopolypeptide from Caribbean marine sponge. Iran J Pharm Res. 2020; 19(3):156-170. doi:10.22037/ijpr.2020.15405.13075

5. Dahiya R, Singh S, Varghese Gupta S, et al. First total synthesis and pharmacological potential of a plant based hexacyclopeptide. Iran J Pharm Res. 2019; 18(2):938-947. doi:10.22037/ijpr.2019.1100643

6. Dahiya R, Kumar S, Khokra SL, Gupta SV, Sutariya VB, Bhatia D, Sharma A, Singh S, Maharaj S. Toward the synthesis and improved biopotential of an Nmethylated analog of a proline-rich cyclic tetrapeptide from marine bacteria. Mar Drugs. 2018;16(9):305. doi:10.3390/md16090305

7. Dahiya R, Singh S. Synthesis, characterization, and biological activity studies on fanlizhicyclopeptide A. Iran J Pharm Res. 2017;16(3):1176-1184.

8. Dahiya R, Singh S, Sharma A, Chennupati SV, Maharaj S. First total synthesis and biological screening of a proline-rich cyclopeptide from a Caribbean marine sponge. Mar Drugs. 2016;14(12):228. doi:10.3390/md 14120228

\section{Conclusion}

Development of novel approaches and techniques to enhance bioavailability of peptides and proteins for non-invasive delivery remains an active field of research. Further, the nanocarrier-based systems have advanced the research efforts in this field. Despite significant progress, the rationale design approaches that efficiently entrap, appropriately release and sufficiently preserve the structural integrity of the peptides and proteins are still underway. The use of advanced nanocarriers as delivery platforms can be foreseen as prospective strategy in developing future peptide and protein products for non-invasive administration. However, extensive studies are still required to develop novel targeted nanocarrier-based peptide and protein formulation for site specific and sustained delivery via non-invasive routes for their successful clinical translation.

\section{Conflict of Interest}

Authors declare no conflict of interest.

9. Patel A, Patel M, Yang X, Mitra AK. Recent advances in protein and peptide drug delivery: A special emphasis on polymeric nanoparticles. Protein Pept Lett. 2014; 21(11):1102-1120. doi:10.2174/09298665216661408 07114240

10. Bajracharya R, Song JG, Back SY, Han HK. Recent advancements in non-invasive formulations for protein drug delivery. Comput Struct Biotechnol J. 2019;17: 1290-1308. doi:10.1016/j.csbj.2019.09.004

11. Homayun B, Lin X, Choi HJ. Challenges and recent progress in oral drug delivery systems for biopharmaceuticals. Pharmaceutics. 2019;11(3):129. doi:10.3390/pharmaceutics11030129

12. Patra JK, Das G, Fraceto LF, et al. Nano based drug delivery systems: Recent developments and future prospects. J Nanobiotechnol. 2018;16(1):71. doi:10.118 6/s12951-018-0392-8

13. Pisal DS, Kosloski MP, Balu-Iyer SV. Delivery of therapeutic proteins. J Pharm Sci. 2010;99(6):2557-75. doi:10.1002/jps.22054

14. Yu M, Wu J, Shi J, Farokhzad OC. Nanotechnology for protein delivery: Overview and perspectives. J Control Release. 2016;240:24-37. doi:10.1016/j.jconrel.2015.1 0.012

15. Roberts CJ. Therapeutic protein aggregation: mechanisms, design, and control. Trends Biotechnol. 2014;32(7):372-380. doi:10.1016/j.tibtech.2014.05.0 05

16. Han Y, Gao Z, Chen L, et al. Multifunctional oral delivery systems for enhanced bioavailability of therapeutic peptides/proteins. Acta Pharm Sin B. 2019;9(5): 902-922. doi:10.1016/j.apsb.2019.01.004 
17. Bruno BJ, Miller GD, Lim CS. Basics and recent advances in peptide and protein drug delivery. Ther Deliv. 2013;4(11):1443-1467. doi:10.4155/tde.13.104

18. Morrow T, Felcone LH. Defining the difference: What makes biologics unique. Biotechnol Healthc. 2004;1(4): 24-29.

19. Dubey S, Mody N, Sharma R, Agrawal U, Vyas SP. Ch 4. Nanobiomaterials: Novel platforms for delivery of peptides and proteins. In: Grumezescu AM (ed.). Nanobiomaterials in Drug Delivery: Applications of Nanobiomaterials. Vol. 9, Elsevier Inc.: 2016, pp. 111146.

20. Maher S, Brayden DJ, Casettari L, Illum L. Application of permeation enhancers in oral delivery of macromolecules: An update. Pharmaceutics. 2019; 11(1):41. doi:10.3390/pharmaceutics11010041

21. Muheem A, Shakeel F, Jahangir MA, Anwar M, Mallick N, Jain GK, et al. A review on the strategies for oral delivery of proteins and peptides and their clinical perspectives. Saudi Pharm J. 2016;24(4):413-28. doi:10.1016/j.jsps. 2014.06.004

22. Padula C, Pescina S, Nicoli S, Santi P. New Insights on the mechanism of fatty acids as buccal permeation enhancers. Pharmaceutics. 2018;10(4):201. doi:10.339 0/pharmaceutics10040201

23. Fominaya J, Bravo J, Rebollo A. Strategies to stabilize cell penetrating peptides for in vivo applications. Ther Deliv. 2015;6(10):1171-1194. doi:10.4155/tde.15.51

24. Saija A, Princi P, Trombetta D, Lanza M, De Pasquale A. Changes in the permeability of the blood-brain barrier following sodium dodecyl sulphate administration in the rat. Exp Brain Res. 1997;115(3):546-551. doi:10.1007/pl00005725

25. Moghimipour E, Ameri A, Handali S. Absorptionenhancing effects of bile salts. Molecules. 2015;20(8): 14451-14473. doi:10.3390/molecules200814451

26. Singh R, Singh S, Lillard JW Jr. Past, present, and future technologies for oral delivery of therapeutic proteins. J Pharm Sci. 2008;97(7):2497-2523. doi:10.1002/jps.21 183

27. Shaji J, Patole V. Protein and peptide drug delivery: Oral approaches. Indian J Pharm Sci. 2008;70(3):269-277. doi:10.4103/0250-474X.42967

28. Renukuntla J, Vadlapudi AD, Patel A, Boddu SH, Mitra AK. Approaches for enhancing oral bioavailability of peptides and proteins. Int J Pharm. 2013;447(1-2):7593. doi:10.1016/j.ijpharm.2013.02.030

29. Buckley ST, Hubálek F, Rahbek UL. Chemically modified peptides and proteins - Critical considerations for oral delivery. Tissue Barriers. 2016;4(2):e1156805. doi:10.1080/21688370.2016.1156805

30. Dahiya S, Dahiya R. Ch 11. Recent Nanotechnological advancements in delivery of peptide and protein macromolecules. In: Rauta PR, Mohanta YK, Nayak D (eds.). Nanotechnology in Biology and Medicine: Research Advancements and Future Perspectives. CRC Press, Taylor \& Francis Group: Boca Raton, FL, United States, 2019; pp. 143-157.

31. Banerjee SS, Aher N, Patil R, Khandare J. Poly(ethylene glycol)-prodrug conjugates: Concept, design, and applications. J Drug Deliv. 2012;2012:103973. doi:10.1155/2012/103973
32. Bumbaca B, Li Z, Shah DK. Pharmacokinetics of protein and peptide conjugates. Drug Metab Pharmacokinet. 2019;34(1):42-54. doi:10.1016/j.dmpk.2018.11.001

33. Patel A, Cholkar K, Mitra AK. Recent developments in protein and peptide parenteral delivery approaches. Ther Deliv. 2014;5(3):337-365. doi:10.4155/tde.14.5

34. Dahiya S, Dahiya R. Ch 37. Organic nanocarriers for targeted delivery of anticancer agents. In: Dua K, Mehta M, de Jesus Andreoli Pinto T, Pont LG, Williams KA, Rathbone MJ (eds.). Advanced Drug Delivery Systems in the Management of Cancer. Elsevier, Academic Press: Netherlands, 2021; pp. 467-497.

35. Dahiya S, Dahiya R, Hernández E. Nanocarriers for anticancer drug targeting: Recent trends and challenges. Crit Rev Ther Drug Carrier Syst. 2021;38(6):49-103. doi:10.1615/CritRevTherDrugCarrierSyst.2021035650

36. Santalices I, Gonella A, Torres D, Alonso MJ. Advances on the formulation of proteins using nanotechnologies. J Drug Del Sci Tech. 2017;42:155-180. doi:10.1016/j.jdd st.2017.06.018

37. Rostami E, Kashanian S, Azandaryani AH, Faramarzi H, Dolatabadi JE, Omidfar K. Drug targeting using solid lipid nanoparticles. Chem Phys Lipids. 2014;181:56-61. doi:10.1016/j.chemphyslip.2014.03.006

38. Naseri N, Valizadeh H, Zakeri-Milani P. Solid Lipid Nanoparticles and nanostructured lipid carriers: Structure, preparation and application. Adv Pharm Bull. 2015;5(3):305-313. doi:10.15171/apb.2015.043

39. Sarmento B, Martins S, Ferreira D, Souto EB. Oral insulin delivery by means of solid lipid nanoparticles. Int $J$ Nanomedicine. 2007;2(4):743-749.

40. Ghasemiyeh P, Mohammadi-Samani S. Solid lipid nanoparticles and nanostructured lipid carriers as novel drug delivery systems: Applications, advantages and disadvantages. Res Pharm Sci. 2018;13(4):288-303. doi:10.4103/1735-5362.235156

41. Khosa A, Reddi S, Saha RN. Nanostructured lipid carriers for site-specific drug delivery. Biomed Pharmacother. 2018;103:598-613. doi:10.1016/j.bioph a.2018.04.055

42. Puri A, Loomis K, Smith B, Lee JH, Yavlovich A, Heldman $\mathrm{E}$, et al. Lipid-based nanoparticles as pharmaceutical drug carriers: from concepts to clinic. Crit Rev Ther Drug Carrier Syst. 2009;26(6):523-580. doi:10.1615/critrev therdrugcarriersyst.v26.i6.10

43. Huynh NT, Passirani C, Saulnier P, Benoit JP. Lipid nanocapsules: A new platform for nanomedicine. Int J Pharm. 2009;379(2):201-209. doi:10.1016/j.ijpharm.2 009.04.026

44. Matougui N, Boge L, Groo AC, et al. Lipid-based nanoformulations for peptide delivery. Int J Pharm. 2016;502(1-2):80-97.

45. Heurtault B, Saulnier P, Pech B, Proust JE, Benoit JP. A novel phase inversion-based process for the preparation of lipid nanocarriers. Pharm Res. 2002; 19(6):875-880. doi:10.1023/a:1016121319668

46. Nishi Y. [Neoral (Cyclosporin microemulsion pre concentrate): pharmacokinetics, pharmacodynamics and its improved clinical outcome]. Nihon Yakurigaku Zasshi. 2001;118(2):107-115. doi:10.1254/fpj.118.107

47. Martins S, Sarmento B, Ferreira DC, Souto EB. Lipidbased colloidal carriers for peptide and protein 
delivery--liposomes versus lipid nanoparticles. Int $J$ Nanomedicine. 2007;2(4):595-607.

48. van Hoogevest $\mathrm{P}$, Wendel A. The use of natural and synthetic phospholipids as pharmaceutical excipients. Eur J Lipid Sci Technol. 2014;116(9):1088-1107. doi:10.1002/ejlt.201400219

49. Peptide Therapeutics Market Report Survey 2021-2025 With Top Countries Data: Industry Size, Share, Future Challenges, Revenue, Demand, Industry Growth and Top Players Analysis. Available from: https://www.wboc.com/story/44310283/peptidetherapeutics

50. Oral Proteins and Peptides Market Overview. Available from: https://www.alliedmarketresearch.com/oralproteins-peptides-market

51. Takebe T, Imai R, Ono S. The current status of drug discovery and development as originated in United States academia: The influence of industrial and academic collaboration on drug discovery and development. Clin Transl Sci. 2018;11(6):597-606. doi:10.1111/cts.1257 